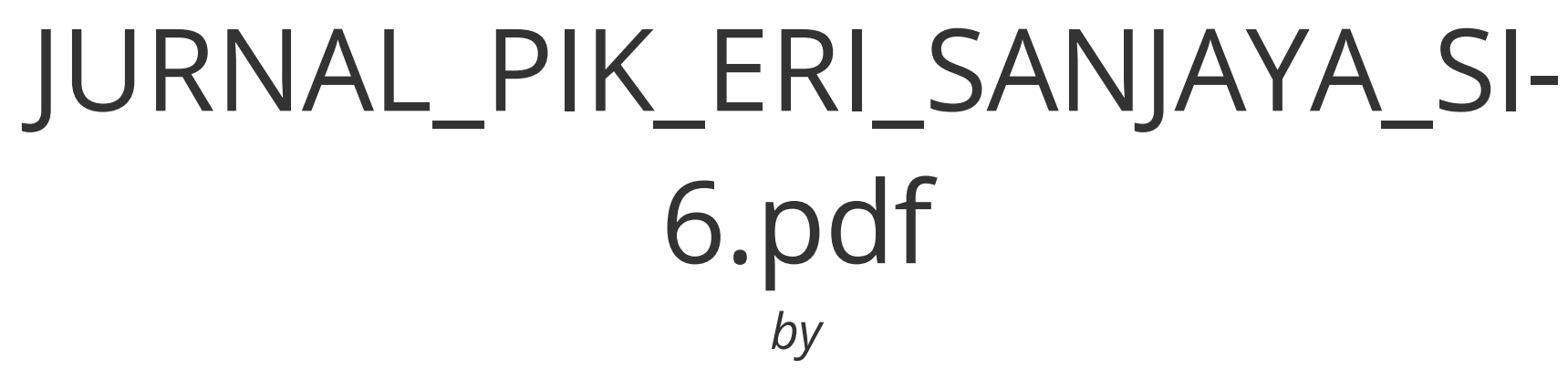

Submission date: 03-Jan-2022 02:07PM (UTC+0700)

Submission ID: 1737035625

File name: JURNAL_PIK_ERI_SANJAYA_SI-6.pdf (811.42K)

Word count: 3183

Character count: 19947 


\title{
PERANGKAT KERAS JARINGAN KOMPUTER
}

ERI SANJAYA (0702212206)

\author{
SISTEM INFORMASI - 6 FST UIN
}

Sumatera Utara Medan 2021 / 2022

erisanjaya53@gmail.com

\begin{abstract}
Abstrak
Jaringan PC ( perangkat keras jaringan computer) adalah kerangka kerja yang terdiri dari beberapa PC yang dimaksudkan untuk memiliki opsi untuk berbagi informasi, data, dan aset. Alasan jaringan PC adalah dengan tujuan agar semua aspek organisasi PC dapat meminta dan memberikan administrasi data dan informasi. ${ }_{5}$ elanggan dan siapa yang mengirim atau mengirimkan bantuan dikenal sebagai server. Kata Kunci : hardware, jaringan komputer, informasi Pendahuluan Perangkat Keras (Hardware) Jaringan Komputer adalah perangkat yang secara fisik dapat dilihat dan diraba, yang membentuk suatu kesatuan, sehingga dapat membangun sebuah jaringan komputer. Untuk dapat membangun sebuah jaringan komputer, ada beberapa perangkat keras jaringan komputer yang harus diketahui seperti NIC, Kabel Jaringan, Konektor, dan lain sebagainya
\end{abstract}

Abstract

A computer network is a system consisting of several computers designed to be able to share data, information, and resources. The purpose of a computer network is so that every

part of a computer network can request and provide information and data services. the client and who sends or sends the service is called the server. Keywords: hardware, computer network, information Introduction Computer Network Hardware is a device that can physically be seen and touched, which forms a unit, so that it can build a computer network. To be able to build a computer network, there are several computer network hardware that must be known such as NICs, Network Cables, Connectors, and so on.

\section{Kata kunci: Pengertian dan Fungsi perangkat kerat jaringan komputer}


FST UIN Sumatera Utara

\section{A.PENDAHULUAN}

Alam semesta Data and Correspondence Innovation atau disebut juga dunia IT tidak bisa dipisahkan dari organisasi PC. Perkembangan dunia jaringan PC sangat cepat, semua PC diandalkan untuk memiliki opsi untuk berkomunikasi satu sama lain dengan media tertentu. Dalam jaringan Neighborhood yang disebut LAN, dikenal sebagai jaringan PC yang melibatkan tautan sebagai media kontak sehingga beberapa PC dapat berbicara satu sama lain. Namun, di samping kemajuan dan inovasi, kebutuhan manusia akan keserbagunaan (mudah dipinqrhkan) dan kemampuan beradaptasi yang tinggi menuntut sesuatu yang lebih membumi.Dan teknologi WiFi memberikan jawaban untuk kebutuhan tersebut.

Sudut pandang da" 90 makna "PC" juga telah berkembang, sesuai dengan iklim, budaya, disiplin ilmu dan landasan logis seseorang, seperti rekayasa perangkat lunak. Sejauh bahasa menurut referensi Kata Ringkas Ba13hart dari dasardasar Sejarah, kata itu digunakan dalam bahasa Inggris pada tahun 1646 sebagai kata untuk "orang yang menghitung" dan kemudian pada tahun 1897 juga untuk "perangkat pemeriksaan mekanis". Selama Perang Besar Kedua, kata tersebut menyinggung pekerja wanita Amerika dan Inggris yang posisinya untuk memastikan bagian meriam konflik besar dengan mesin tersebut. Orang Prancis atau Prancis menggunakan "ordinateur", yang secara umum berarti "koordinator", atau "mesin terpisah". Spanyol menggunakan "ordenador", dengan arti yang sama, 10eskipun di negara-negara tertentu mereka menggunakan "anglicism computa dora".
Eri Sanjaya

Dalam bahasa Italia, PC adalah "calcolatore", dari "number cruncher".

Bahasa Swedia, komputer dipanggil "dator" dari "data". Dalam bahasa Cina, PC disebut "dien nau" atau "cerebrum listrik". Referensi Oxford English Word (OED 2), rilis kedua, mencirikan PC sebagai gadget yang digunakan untuk memastikan atau mengendalikan aktivitas yang dikomunikasikan dalam struktur matematis atau koheren.

PC adalah instrumen yang digunakan untuk menangani informasi sesuai dengan metode yang telah dibentuk. Kata PC awalnya digunakan untuk menggambarkan seseorang yang pekerjaannya melakukan perhitungan angka, dengan atau tanpa instrumen, namun arti kata ini kemudian jipindahkan ke mesin yang sebenarnya. https://id.wikipedia.org/wiki/Komputer

Sebelum masuk ke percakapan tentang apa jenis dan macam gadget jaringan PC, kita harus terlebih dahulu tahu apa artinya. Jaringan PC adalah setidaknya dua gadget PC yang seling berhubungan atau terkait satu sama lain dan digunakan untuk sumber informasi yang berbeda.

Setiap titik akhir dalam suatu organisasi memiliki pengenal, yang umumnya disinggung sebagai alamat IP atau alamat kontrol akses media. Titik akhir dapat menggabungkan server, PC, telepon, dan peralatan organisasi lainnya. Organisasi PC (Jarkom) dapat dibuat dengan memanfaatkan perpaduan antara inovasi kabel dan jarak jauh.

Organisasi dapat bersifat pribadi atau publik. Dalam penggunaan sebuah organisasi swasta, biasanya mengharuskan penerimaan klien untuk memasukkan akreditasi sebagai ungkapan rahasia yang dimasukkan secara fisik oleh kepala atau 
FST UIN Sumatera Utara

langsung oleh klien. Untuk pemanfaatan organisasi publik, misalnya web, tidak membatasi

akses.[2]

https://www.sekawanmedia.co.id/penger tian-jaringan-komputer/

\section{B. TINJAUAN PUSTAKA}

PC adalah gadget elektronik yang mengontrol data, atau informasi. Itu dapat menyimpan, memulihkan, dan menangani informasi. PC dimaksudkan untuk menjalankan aplikasi dan memberikan pengaturan melalui peralatan yang tergabung dan bagian pemrograman. la bekerja dengan bantuan program dan alamat angka desimal melalui perkembangan angka paralel. la juga memiliki memori yang menyimpan informasi, proyek, dan hasil penanganan.http://hot.liputan6.com

Perangkat jaringan, atau disebut juga perangkat keras jaringan atau gadget jaringan PC, adalah perangkat elektronik yang diperlukan untuk korespondensi dan kerjasama antar gadget pada organisasi PC. Secara khusus, mereka menengahi transmisi informasi dalam organisasi PC. https://en.wikipedia.org/wiki/Networking _hardware

Seperti yang ditunjukkan oleh Abdul Kadir (2003:348) "jaringan PC adalah hubungan dua hub (pada umumnya seperti PC) atau lebih yang desain utamanya adalah untuk memperdagangkan informasi". Berbagi aset (printer, prosesor pusat), menyampaikan (SMS), dan memiliki pilihan untuk mendapatkan data (browser internet). Motivasi di balik jaringan PC adalah untuk mencapai tujuannya, semua aspek organisasi PC dapat meminta dan menawarkan jenis bantuan. Pihak yang
Eri Sanjaya

meminta/mendapatkan bantuan disebut sebagai pelanggan dan pihak yang memberikan/mengirim bantuan disebut sebagai server. Paket ini dikenal sebagai kerangka kerja server pelanggan, dan digunakan di hampir semua aplikasi jaringan PC. Indra W (2012) "Yang dimaksud dengan jaringan PC adalah bermacam-macam PC dan perangkat keras lainnya yang berhubungan satu sama lain dan menyusun kerangka kerja yang terikat". Jaringan PC memungkinkan data dan informasi untuk berpindah mulai dari satu organisasi kemudian ke organisasi berikutnya, sehingga memungkinkan klien jaringan PC untuk memperdagangkan arsip dan informasi. Bukan hanya itu, jaringan $\mathrm{PC}$ juga

memungkinkan klien untuk mencetak pada printer yang sama dan digunakan bersamasama.

Jaringan PC adalah bern 16 cam-macam setidaknya dua PC yang saling berhubungan untuk memberikan informasic Hubungan antara setidaknya dua PC dapat terjadi melalui media kabel atau jarak jauh (tan 16 tautan). Informasi yang disampaikan dapat berupa teks, suara, gambar, atau informasi video. Media jaringan PC dapat melalui link atau jarak jauh untuk memungkinkan klien jaringan PC untuk bertukar data, seperti data dan informasi, juga dapat bertukar data satu sama lain.

pencetakan pada printer serupa dan peralatan bersama

juga pemrograman terkait jaringan. Setiap PC atau gadget yang terkait dengan suatu organisasi dikenal sebagai hub. Dalam sebuah organisasi PC dapat memiliki dua, puluhan, ribuan atau bahkan sejumlah besar hub. 
23

\section{METODE PENELITIAN}

Pada penelitian kali ini, metode yang saya terapkan adalah metode kunjungan kepada sumber sumber bahan penelitian. Kujungan yang saya lakukan ialah pada halaman world wide web (site visit). Melalui sumber dari situs:

\section{https://id.wikipedia.org/wiki/Komputer \\ https://en.wikipedia.org/wiki/Networking hardware https://binus.ac.id/bandung/2019/11/sejarah -mulainya-jaringan-komputer/}

\section{https://qwords.com/blog/perangkat- keras-jaringan/}

pemrosesan.http://hot.liputan6.com

https://www.sekawanmedia.co.id/penger tian-jaringan-komputer/

DLL.

Tidak hanya dari kunjung kunjungan dari link, penelitian yang saya lakukan juga bersumber dari buku bacaan "Pengenalan Komputer dan Teknologi Informasi" karya dari bapak Samsudin dkk. Terlebih lagi dapat disimpulkan dari buku bacaa 20 itu, jaringan PC adalah kerangka kerja yang terdiri dari PC dan perangkat organisasi lainnya yang bekerja sama untuk mencapai tujuan bersama. Jari 18 an PC adalah kumpulan PC independen yang saling terhubung satu sama lain menggunakan konvensi korespondensi melalui media korespondensi sehingga dapat berbagi data, proyek, dan menggunakan peralatan secara bersamasama (interkoneksi berbagai PC). Jaringan PC adalah berbagai macam terminal koresponjensi yang terletak di area berbeda yang terdiri dari lebih dari satu PC yang saling berhubungan.

\section{HASIL DAN PEMBAHASAN}

\section{PENGERTIAN JARINGAN KOMPUTER}

Jaringan PC adalah setidaknya dua PC yang terhubung satu sama lain dan digunakan untuk informasi yang berbeda. Kehadiran jaringan PC dirakit memanfaatkan perpaduan antara peralatan dan pemrograman. Dalam produksi organisasi PC, sakelar dan sakelar menggunakan konvensi dan perhitungan dengan tujuan agar mereka dapat memperdagangkan data dan dapat menyampaikan informasi ke titik akhir sesuai keinginan. Tujuan adanya jaringan komputer ialah:

a. Membagi sumber daya: contohnya berbagi pemakaian printer, CPU, memori, harddisk.

b. Komunikasi: contohnya surat elektronik, instant messaging, chatting.

c. Akses informasi: contohnya web browsing

d. Hiburan interaktif

e. reliability/kehandalan tinggi: yaitu tersedia sumber sumber alternatif kapan pun di perlukan. 
FST UIN Sumatera Utara

\section{PERKEMBANGAN PERANGKAT KERAS JARINGAN KOMPUTER}

Latar belakang sejarah organisasi PC (PC Organization) dimulai dengan fiperkenalkannya ide jaringan PC selama tahun 1940-an di Amerika yang dibuat oleh usaha untuk perbaikan PC di lab Chime dan sekelompok eksplorasi dari Harvard College yang dipimpin oleh Pendidik Howard Aiken . Pada awalnya inovasi tersebut dimanfaatkan untuk penggunaan gadget PC untuk keperluan biasa. Pikirannya adalah melakukan tugas yang berbeda tanpa menghabiskan banyak waktu luang, sehingga terjadi interaksi yang berurutan, sehingga program dapat berjalan di berbagai PC.

Kemudian, pada saat itu, selama tahun 1950-an ketika PC mulai dibuat hingga produksi PC super, sebuah PC perlu melayani beberapa tempat yang dapat diakses (terminal), untuk itu gagasan alokasi siklus yang bergantung pada waktu ditemukan, yang dikenal sebagai TSS (Kerangka Berbagi Waktu). Jadi menariknya jenis jaringa ${ }_{27}$ PC yang diterapkan. Dalam kerangka TSS beberapa terminal dihubungkan secara seri ke PC atau gadget lain yang dikaikkan dengan organisasi PC (memiliki). mengusulkan sebuah organisasi yang sangat luas dan dapat digunakan oleh semua orang di planet ini. Vinton Cerf dan juga Sway Kahn adalah dua orang yang membuat pemikiran besar, yang benar-benar menjadi pelopor produksi web atau organisasi dunia. Sekarang,

Web juga telah diubah menjadi organisasi terbesar di planet ini, dan dapat menghubungkan semua orang di berbagai wilayah di planet ini.https://binus.ac.id/bandung/2019/11/s ejarah-mulainya-jaringan-komputer/

\section{KLASIFIKASI JARINGAN KOMPUTER}

\section{1) Berdasarkan Skala}

a. Local Area Network (LAN) adalah jaringan PC yang menyatukan satu computer dengan computer yang lain dengan jangkauan yang terbatas

b. Metropolitant Area Network (MAN): cara kerjanya mirip sam LAN, yang membedakan henyalah jangkauan nya yang lebih lebar, yaitu $10-50 \mathrm{~km}$.

c. Wide Area Network (WAN): jangkauan nya bisa hingga satu negara bahkan satu benua, seperti internet.

d. Personal Area Network (PAN): Jaringan personal atau Personal Area Network (PAN) merupakan jaringan computer yang menyatukan antar dua atau lebih sistem computer yang meiliki jarak sangat dekat, yaitu hanya berjarak 4 sampai 6 meter. contohnya pada saat menyambungkan hp dengan computer, computer dengan print dll.

Seperti terlihat pada gambar dibawah ini: 


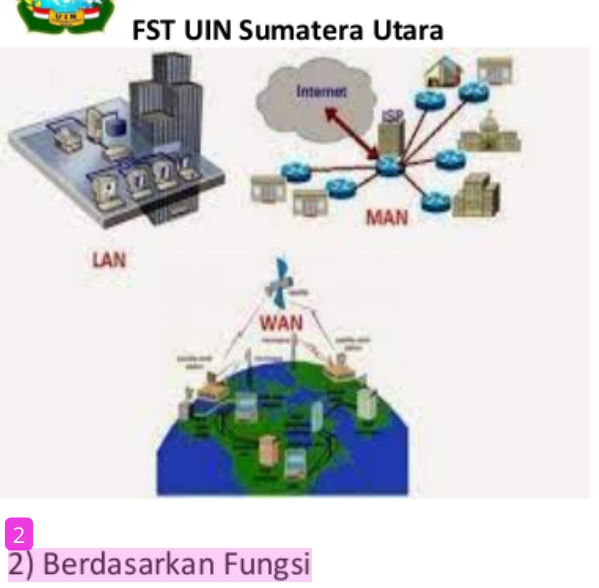

a. Client - server, merupakan jaringan computer dengan computer yang lain di pakai kusus sebagai server inti.

b. Peer -22 eer, merupakan kumpulan computer yang dimana setiap client bisa menjadi server dan juga menjadi klien secara waktu bersama sama.

c. Berdasarkan kegunaan dan hubungan satu sama lain komputer dalam memproses data data

3) Berdasarkan topologi jaringan komputer, jaringan computer bias di bedakan menjadi:

Topologi bus, topologi bintang/star, topologi mesh, topologi pohon, topologi linear, topologi cincin/ring.

\section{d. Berdasarkan media transmisi data}

- Jaringan berkabel ( Wired Network)

- Jaringan Nirkabel (WI-FI)

PC server adalah peralatan organisasi utama di web. Tanggung jawab server adalah menjadi titik fokus dari semua organisasi PC dan di server ini informasi yang sangat penting disimpan.

4.)Berdasarkan kriterianya, jaringan
komputer di bedakan menjadi 4 yaitu:
a. berdasarkan distribusi sumber
informasi/ data
- jaringan terpusat
- jaringan terdistribusi
b.Berdasarkan jangkauan geografis di
bedakan menjadi
- Jaringan LAN
- Jaringan MAN
- Jaringan WAN
JARINGAN KOMPUTER
k. Berdasarkan peranan dan hubungan tiap
- Jaringan Client-Server
- Jaringan Peer to Peer
JENG

\section{1) Komputer Server}

Ketika ada ajakan dari pelanggan, server akan

PC server adalah peralatan organisasi utama di web. Tanggung jawab server adalah menjadi titik fokus dari semua organisasi PC dan di server ini informasi yang sangat penting disimpan. Ketika ada ajakan dari pelanggan, server akan mengirimkannya melalui beberapa peralatan organisasi dan pemrograman. Sebagai aturan umum, PC server memiliki 
FST UIN Sumatera Utara

kapasitas sebagai kapapitas semua kumpulan data. Informasi di server akan dikirim oleh ajakan

dari pelanggan. Semakin baik spesifikasi PC server, semakin menonjol batas kapasitas dan semakin cepat siklusnya. Itulah alasan server adalah salah satu hal yang paling kuat pada presentasi organisasi web. Penentuan PC server juga harus unik, PC biasa tidak dapat dipaksa untuk menjadi server. PC server harus dapat bekerja 24 jam setiap hari, sehingga peralatan yang digunakan juga harus luar biasa. Mulai dari prosesor, hardisk, RAM, motherboard, power supply dan sisa gadget server lainnya. Dengan begitu server dapat melayani pelanggan dengan maksimal tanpa server down.

\section{2) Komputer Client}

Pelanggan menyiratkan PC klien. Sebagaimana dijelaskan di atas, pelanggan adalah individu yang mengakses informasi di server melalui meb. Jumlah pelanggan ini sebagian besar terdiri dari beberapa PC yang terhubung melalui jaringan web yang sama dengan server. Jika PC pelanggan tidak terhubung dengan server, pelanggan tidak dapat mengakses informasi PC server. PC pelanggan hanya PC konvensional tanpa akses jaringan web. Untuk berinteraksi dengan organisasi web, PC pelanggan harus dikaitkan dengan organisasi tautan LAN atau mungkin juga organisasi WiFi.

3) Kabel

Saat membicarakan organisasi, tentu tidak akan lepas dari tautan organisasi. Sebelum ada inovasi WiFi, semua web dikaitkan dengan taytan organisasi. Sebagian besar link yang digunakan adalah UTP (Unshielded Turned Pair), link koaksial dan Fiber Optic. Dalam memilih link untuk membantu koneksi
Eri Sanjaya

1epat, dianjurkan untuk menggunakan link fiber optic yang dapat mengirimkan informasi hingga $1 \mathrm{Gbps}$, namun biayanya paling mahal dan koneksinya merepotkan. Untuk membangun sebuah organisasi skala lingkungan, penggunaan link UTP disukai karena lebih murah dan lebih mudah dalam hal pemeliharaan.

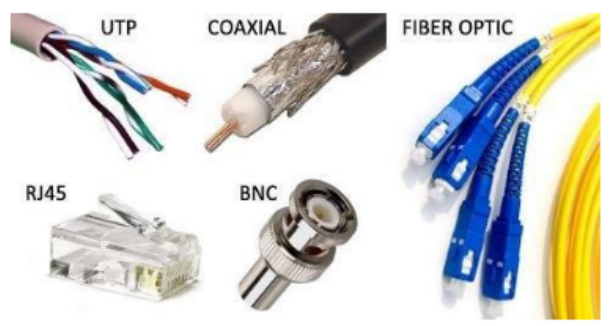

Image:https://netsolution.co.id/kabeljaringan-komputer/

\section{4) Konektor}

Konektor adalah perangkat keras jaringan yang berguna untuk dipasang pada bagian ujung kabel untuk menghubungkan pada adapter kabel. Ada ada banyak jenis konektor yang digunakan dalam perangkat jaringan komputer saat ini, diantaranya adalah seperti berikut:

- Konektor RJ-45 di pakai untuk kabel UTP, dan sekarang ini paling banyak dipakai untuk perangkat jaringan internet dimanapun.

- Konektor BNC/T di pakai untuk kabel tipe coaxial.

- KonektorST dipakai untuk keperluan kabel fiber optic, ini menjadikan konektor dengan prize paling mahal dibandingkan dengan kabel kabel lainnya.

Untuk melakukan pengecekan apakah pemasangan sudah benar atau salah dalam 
FST UIN Sumatera Utara

memasang konektor Anda bisa
memakai konektor tester.

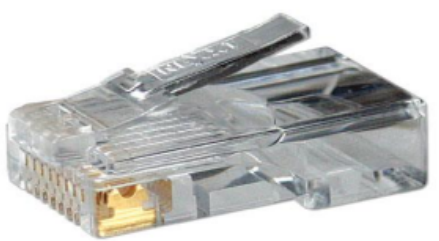

5) Switch

Switch adalah peralatan yang iringan berguna untuk memisahkan jaringan dari satu server ke beberapa pelanggan di lingkungan jaringan. Biasanya ruang yang tendapat dalam sakelar adalah produk dari 4,8,16,32, dll. Semakin banyak port, semakin mahal sakelar tersebut. Perlu juga diperhatikan bahwa tombol tersebut memiliki kontras dengan bagian tengah, meskipun secara fisik sama namun kapasitasnya berbeda. Penggunaan mendasar dari sakelar yang mengenalinya dari titik pusat adalah kapasitasnya yang lebih cerdik dalam membatasi dan mengelola ukuran paket informasi yang dikirim ke setiap pelanggan terkait. Jadi Anda dapat mengatur kecepatan web setiap

klien.
Eri Sanjaya

Imageswitch:https://www.masahen.com/ 2019/07/pengertian-switch-dan-hubserta.html

\section{6) HUB}

HUB adalah peralatan jaringan yang memiliki kapasitas untuk berbagi jaringan dalam stu server. Umumnya pusat secara luas digunakan pada jaringan LAN. Perbedaan dengan perubahan adalah pada kemampuan untuk menangani pelanggan, titik pusat dapat berbagi organisasi tanpa harus memiliki pilihan untuk mengawasi dan membatasi paket informasi yang dikirim, sehingga penyampaian tidak dapat wajar antara satu pelanggan dengan yang lain. Satu lagi kontras deman sakelar adalah bahwa pusat-pusat ini jauh lebih murah. Selain itu, kekurangan dari pusat ini adalah dengan asumsi bahwa itu dirugikan, semua pelanggan akan berpisah. Selain itu, pusat tidak memiliki sorotan namun cerdas sebagai inovasi yang tampaknya akan beralih.

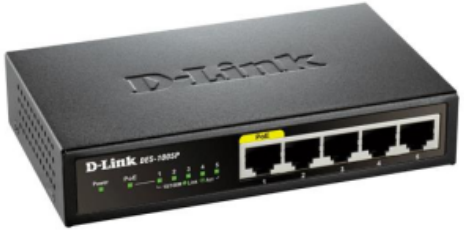

\section{7) Bridge}

Sesuai sama namanya. bridge memiliki kapasitas sebagai penghubung jaringan. Ini berarti bahwa ekstensi ini dapat mengkonsolidasikan jaringan terdekat ke jaringan lingkungan lain yang lebih besar. Perancah penggunaan yang berbeda dapat digunakan untuk memisahkan jaringan lokal menjadi 
FST UIN Sumatera Utara

beberapa jaringan lingkungan yang lebih sederhana. Fungsi utama dari bridge adalah digunakan sebagai jembatan antar jaringan yang memakaitopologi jaringan yang tidak sama

bridge ini sangat membantu ketika Anda berada di kantor/kantor besar yang terdiri dari beberapa struktur dan tempat kerja yang ditemukan secara mandiri. Seluruh struktur dan tempat kerja semuanya dapat menjadi satu dengan bantuan gadget bridge.

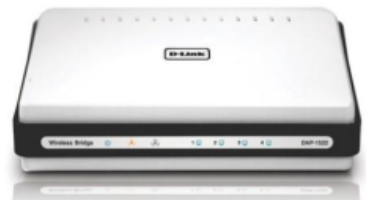

\section{8) Acces Point}

Acces point dapat mengirim tandatanda jarak jauh yang didapat dari sakelar atau jaringan yang terhubung sehingga tanda yang diperoleh klien bisa lebih baik. Segmen ini tampaknya sah untuk wilayah yang memiliki jaringan yang tidak berdaya. Untuk aplikasi ini lebih mudah dan pengaturannya tidak terlalu merepotkan jika dibandingkan dengan switch. Mungkin koridor ini mengambil jalan tengah tetapi menggunakan jaringan WiFi. Sejauh keamanan liang, Anda dapat menambahkan frase rahasia untuk setiap pelanggan yang harus berhubungan dengan jaringan.

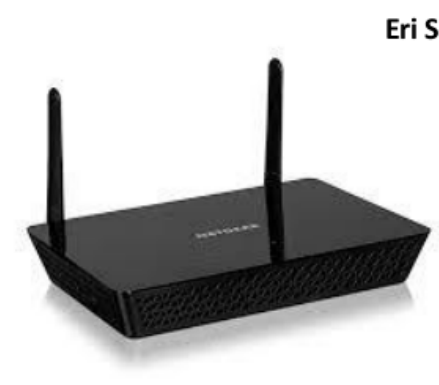

9) Router

Peralatan jaringan berikut adalah router. Router adalah perangkat jaringan yang berguna untuk mengirim jaringan web dengan konvensi TCP/IP pada PC pelanggan. Jadi setiap pelanggan mendapatkan IP alternatif yang tidak sama satu sama lain.

Secara praktis, sakelar praktis setara dengan bagian namun memiliki lebih banyak elemen. Sakelar menikmati manfaat memiliki opsi untuk berbagi paket informasi yang akan diberikan ke setiap jalur atau titik pusat terkait. Switch ini cocok untuk wilayah kantor, struktur, sekolah dan pusat perbelanjaan yang memiliki banyak klien jaringan.

\section{0) Repeater}

Repeater adalah perangkat keras jaringan yang berguna untuk memperlancar sinyal jaringan. Dengan memaki repeater tersebut sinyal yang tempatnya jauh bisa diperkuat lagi sehingga dapat terakses 
FST UIN Sumatera Utara

dengan jangkauan yang lebih luas

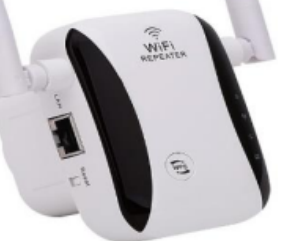

\section{Network Card}

Network card merupakan kartu internet yang sering digunakan dalam pc atau komputer. kegunaan utamanya adalah sebagai kartu jaringan untuk menangkap jaringan network fisik ataupun jaringan nonfisik. Jadi kartu internet ini merupakan alat fisik jaringan tambahan yang bisa menyatukan antara computer 1 dengan computer lainnya dalam satu jaringan internet.

\section{2) Modem}

Modem adalah alat perangkat jaringan yang mempunyai kegunaan untuk mengubah dari sinyal analog menjadi digital dan ataupun sebaliknya. Saat ini modem memiliki bentuk berupa USB yang gampang dipakai, dulunya modem masih menggunakan konekgi Dial-up. https://qwords.com/blog/perangkatkeras-jaringan/

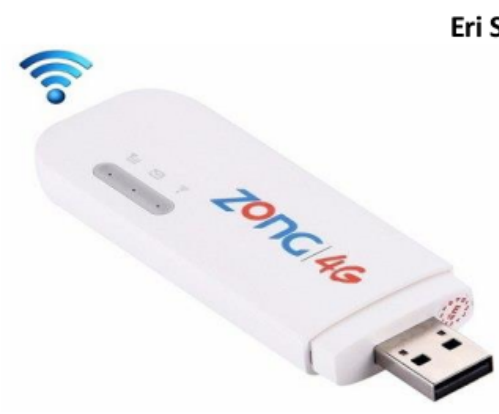

\section{E. KESIMPULAN}

Perangkat keras jaringan komputer adalah perangkat yang berfungsi sebagai media agar komputer dapat terhubung satu sama lain sehingga membentuk sebuah jaringan kor ${ }_{14}$ uter perangkat keras jaringan komputer adalah perangkat yang digunakan untuk menghubungkan komputer ke komputer lainnya dalam jaringan untuk tujuan berbagi data, berbagi informasi serta berbagi peripheral dalam jaringan.

Jaringan komputer merupakan sebuah sistem yang terdiri dari komputer dan perangkat jaringan lain yang bekerja bersama sama untuk menggapai suatu tujuan terrtentu

Jaringa komputer merupakan sekelompok komputer otonom yang saling berhubungan antara satu dan lainnnya menggunakan protokol komunikasi melalui media komunikasi sehingga dapat saling berbagi informasi, program program, pengguna perangkat keras secara bersama (interkoneksi sejumlah komputer).

\section{F. REFERENSI}


[1]Samsudin,dkk, 2019. Pengenalan Komputer dan Teknologi Informasi.

Mrdan: Perdana Publishin.

137https://docplayer.info/46360976Perangkat-keras-jaringan-komputer.html

[3] https://jaringankomputer-

pc.blogspot.com/2013/07/perangkat-

keras-jaringan-komputer.html

25

[4] https://id.wikipedia.org/wiki/Komputer

[5] https://en.wikipedia.org/wiki/Networki ng hardware

6] https://binus.ac.id/bandung/2019/11/sejar ah-mulainya-jaringan-komputer/

[7]https://qwords.com/blog/perangkatkeras-jaringan/

[8]pemrosesan.http://hot.liputan6.com

[9]https://www.sekawanmedia.co.id/pen gertian-jaringan-komputer/

[10] http://ejournal.stmiklombok.ac.id/ind ex.php/jire/article/view/32

[11] Yahfizham. 2019. Dasar dasar computer.

[12] LPKIT Komputer - 2017 academia.edu

[13] H Anggriyani - 2020 - osf.io

[14] A Hadi - 2016 - books.google.com

[15] FR Doni - Simnasiptek 2016, 2016 seminar.bsi.ac.id
BIODATA DIRI

Eri Sanjaya

Eri Sanjaya, saat ini ş̧ aktif program S-1 Sistem Informasi, Fakultas Sains dan Teknologi, Universitas Islam Negeri Sumatera Utara Medan. 
JURNAL_PIK_ERI_SANJAYA_SI-6.pdf

ORIGINALITY REPORT

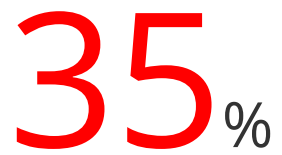

SIMILARITY INDEX
$33 \%$

INTERNET SOURCES

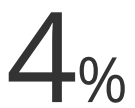

PUBLICATIONS
$7 \%$

STUDENT PAPERS

PRIMARY SOURCES

1 qwords.com

Internet Source

2 repository.uinsu.ac.id Internet Source

3 www.slideshare.net

4 e-journal.janabadra.ac.id

Internet Source

5 docplayer.info

Internet Source

6 aqbilfn.wordpress.com

Internet Source

7 Submitted to Universitas Negeri Jakarta

Student Paper

8

kuhitung123.blogspot.com 
10 elearning.smkidttelukpakedai.sch.id Internet Source

11 Sopian Sumardi, Mohammad Taufan Asri

Zaen. "Perancangan Jaringan Komputer Berbasis Mikrotik Router OS Pada SMAN 4

Praya", Jurnal Informatika dan Rekayasa

Elektronik, 2018

Publication

12 binus.ac.id

Internet Source

eternallovefinder.wordpress.com

Internet Source

karrikasm.wordpress.com

Internet Source

15 Submitted to Universitas Pamulang

Student Paper

16 kikimaylan.blogspot.com Internet Source

17 jaringankomputer-pc.blogspot.com Internet Source

18 keepyourmindson.blogspot.com

Internet Source 
21 www.jurnal.uinsu.ac.id

22 tkjnescip4.blogspot.com

23 es.scribd.com

24 leonardo282.blogspot.com

25 andresanjaya.blogspot.com

26 elearning.smkn1-bontang.sch.id Internet Source

27 titiksusantiwidiastuti.wordpress.com

28 bisnissuksesdot.wordpress.com

30 wwwmyteknologi-informasi.blogspot.com Internet Source 
Exclude bibliography On 